\title{
LAS ESCUELAS PARTICULARES INGLESAS EN BUENOS AIRES 1820-1884
}

\author{
Alina Silveira ${ }^{1}$ \\ CONICET - Argentina \\ alinasilveira@hotmail.com
}

Recepción: 27/05/2011

Evaluación: 20/08/2011

Aceptación: 29/05/2012

Artículo de Revisión

doi: 10,9757

\section{RESUMEN}

La educación en Buenos Aires antes de la Ley de Educación Común de 1884 ha sido un tema escasamente abordado por la historiografía argentina. El objetivo del presente artículo es indagar sobre el mundo educativo porteño estudiando las escuelas de particulares en manos de ingleses, escoceses, irlandeses, norteamericanos y sus descendientes que se instalaron en la ciudad a partir de 1820. Para ello trabajamos con los avisos publicados en la prensa angloparlante de escuelas inglesas, los registros policiales y el Censo Nacional de Escuelas de 1872 así como con opiniones de angloparlantes sobre los niños y la educación de los hijos de extranjeros. A través del estudio de estas fuentes encontramos que las escuelas inglesas formaron parte del heterogéneo mundo educativo porteño y desempeñaron un lugar destacado en la educación de la población tanto de extranjeros como nativos. Estas ofrecían una educación con asignaturas variadas y de mayor complejidad que las escuelas públicas y las de otras particulares llegando a educar a miembros destacados de la sociedad local presentándose como una alternativa al sistema educativo estatal precario o inexistente durante buena parte del siglo XIX.

Palabras clave: Revista Historia de la Educación Latinoamericana, educación, Buenos Aires, inmigración británica.

1 Magister en investigación histórica, becaria doctoral del Conicet y docente de La Universidad de BA, su campo de investigación es sobre la inmigración inglesa y escocesa a Buenos Aires (18201880), ha publicado varios libros en los que se destacan "Nuevos actores entran en escena: los británicos en el Río de la Plata (1800-1850)" en Buenos Aires, una sociedad que se transforma. Entre la colonia y la Revolución de Mayo, Buenos Aires, Prometeo/UNGS, 2011. (en prensa). Logonautas Historia 3: Argentina y el mundo entre los siglos XIX y XXI, Boulogne, Puerto de Palos, 2009. Autora de dos capítulos. 


\section{PRIVATE BRITISH SCHOOLS IN BUENOS AIRES 1820-1884}

\begin{abstract}
Education in Buenos Aires was an ignored subject by histotians in Argentina even before Common Education Law 1884. This article aims to investigate education world in Buenos Aires by studying private schools held by English, Scotches, Irish, and Americans and therefore their decendants that settled in the city since 1820. For this investigation we worked with forgein schools press advertisement for English speakers, police records, and National oficial registration Document for schools in 1872 and English speakers experts opinion on children and education of foreing people' children, because of these sources study we found that English private schools were part of a diversified Educational world in Buenos Aires, in order to develop a privileged spot for native and foreigners education. These schools offered a variety of subjects being more complex than public schools' and other similar private schools offer getting to educate several important members of local society, presenting itself as a new alternative to the poor and ineficient State's educational system during $19^{\text {th }}$ century.
\end{abstract}

Key words: Revista Historia de la Educación Latinoamericana, education, Buenos Aires, british immigration

\section{AS ESCOLAS PARTICULARES INGLESAS EM BUENOS AIRES 1820-1884}

\section{RESUMO}

A educação em Buenos Aires antes da Lei de Educação Comum de 1884 foi um tema pouco abordado pela historiografia argentina. O objetivo do presente artigo é indagar sobre o mundo educativo portenho estudando as escolas de particulares em mãos de ingleses, escoceses, irlandeses, norte-americanos e seus descendentes que se instalaram na cidade a partir de 1820. Para isso trabalhamos com os avisos publicados na imprensa anglofalante de escolas inglesas, os registros policiais e o Censo Nacional de Escolas de 1872, assim como com opiniões de anglofalantes sobre os meninos e sobre a educação dos filhos de estrangeiros. Através do estudo dessas fontes percebemos que as escolas inglesas formaram parte do heterógeno mundo educativo portenho e desempenharam um lugar destacado na educação da população tanto de estrangeiros como de nativos. Estas ofereciam uma educação com matérias variadas e de maior complexidade que as escolas públicas e outras particulares, chegando a educar membros destacados da sociedade local, apresentandose como uma alternativa ao sistema educativo estatal precário ou inexistente durante boa parte do século XIX.

Palavras-chave: Revista História da Educação Latino-americana, educação, Buenos Aires, imigração britânica.

\section{INTRODUCCIÓN}

El problema de la educación y las escuelas en la Argentina ha sido un tema largamente explorado por historiadores para comprender la construcción de una identidad nacional a partir de fines del siglo XIX y el siglo XX. No obstante, esta problemática estuvo ausente en las primeras décadas del siglo XIX cuando el ex Virreinato del Río de la Plata luchaba por su independencia y organización. La construcción de una identidad nacional y de un ser nacional a través de la educación no fue un problema para los políticos e intelectuales de la época. La falta de recursos y docentes calificados, las guerras por la independencia y las luchas civiles hicieron fracasar durante la primera mitad del siglo XIX los proyectos educativos estatales. El campo educativo, entonces, descentralizado y heterogéneo, permaneció abierto a las diversas propuestas 
educativas que provenían de la iglesia católica, las escuelas de extranjeros y/o las escuelas de particulares.

El objetivo del presente artículo es indagar sobre el desarrollo de las escuelas particulares de ingleses entre 1820 y 1884. Iniciamos nuestra investigación en la década de 1820 cuando comenzaron a arribar a la región gran cantidad de británicos atraídos por los proyectos colonizadores, la firma del Tratado con Gran Bretaña y el período de relativa paz y estabilidad bajo la administración rivadaviana. Nos detenemos en el año 1884 cuando la sanción de la Ley de Educación Común en el contexto del proceso de organización nacional volcó al tema de la educación en la agenda política modificando el escenario educativo local.

El estudio de las escuelas de particulares en la Argentina ha sido un tema poco transitado por la historiografía local. Los trabajos académicos sobre el sistema educativo han concentrado su atención en el estudio de las escuelas públicas luego de la sanción de la ley de Educación Común 1420 de 1884 que establecía la educación pública, gratuita y obligatoria. Las interpretaciones tradicionales sobre este tema se dividieron en dos tendencias: las liberales y las revisionistas. Las primeras resaltaron el desarrollo del sistema educativo público bajo los gobiernos liberales y criticaron duramente las políticas educativas rosistas. Esta corriente historiográfica interpretó al período que le siguió a la caída de Rosas como uno de gran efervescencia que culminó en la sanción de la Ley de Educación Común la cual brindó una educación libertadora e igualitaria en un camino de incuestionable progreso social ${ }^{2}$. Los revisionistas rechazaron las interpretaciones pesimistas sobre el desarrollo del sistema educativo bajo los gobiernos de Rosas, resaltando el fortalecimiento de las instituciones privadas durante ese período ${ }^{3}$.

En la segunda mitad del siglo veinte, la historia de la educación cuestionó la imagen simplista que describían los historiadores liberales sobre el exitoso desarrollo de la educación pública. En los últimos cuarenta años nuevas interpretaciones sobre el sistema educativo argentino tendieron a complejizar el campo ofreciendo interpretaciones más analíticas. La educación y las escuelas comenzaron a estudiarse en relación a la política y la estructura económica productiva local, las tendencias pedagógicas se transformaron en objetos de estudio, se indagó sobre el ámbito escolar interno (dispositivos disciplinarios, formación docente, marginaciones, etc.), se estudiaron las

2 Entre los historiadores liberales podemos mencionar a Juan P. Ramos, Evaristo Iglesias, Antonio Portnoy.

3 Entre los revisionistas véanse los trabajos de Antonio Salvadores. 
políticas educacionales, se cruzó el problema de la educación con los estudios de género y surgieron nuevas problemáticas relacionadas con el cotidiano escolar, la didáctica y el pensamiento sobre la infancia ${ }^{4}$. Sin embargo, estas aproximaciones pusieron el foco en el sistema educativo y las escuelas luego de 1884. Desde la historia de la educación poco se ha investigado sobre el fenómeno educativo luego de la independencia.

Por otro lado, en los últimos treinta años los historiadores también han indagado sobre el tema, en particular han estudiado el papel desempeñado por las escuelas en la construcción de una identidad nacional, la adhesión a la patria, la imposición de una única lengua nacional, la elaboración de un mito cívico republicano y la creación de una tradición patriótica ${ }^{5}$. Los trabajados académicos centraron su atención en el sistema educativo a partir de 1884, pocos investigadores estudiaron el escenario educativo antes de dicha fecha. Los trabajos de Carlos Newland y José Bustamante son las mejores obras con las cuales disponemos sobre la historia del sistema educativo en Buenos Aires durante la primera mitad del siglo XIX. Sus trabajos analizan el desarrollo histórico de las escuelas en un Buenos Aires convulsionada por las crisis políticas y la guerra, en el contexto de una sociedad en transformación que incipientemente se abría a la presencia de los extranjeros y los efectos de esta situación en el desarrollo inicial de las escuelas elementales antes de la ley $1420^{6}$. Mark Szuchman, a su vez, ha estudiado la educación en Buenos Aires durante la primera mitad del siglo XIX en tanto lente a través del cual analizar la sociedad porteña del siglo XIX ${ }^{7}$. No obstante, ninguno de éstos focalizó en las escuelas de extranjeros y el papel desempeñado por éstos en el escenario educativo local.

Desde los estudios migratorios, algunos investigadores estudiaron las escuelas de extranjeros y analizaron la fundación de escuelas étnicas ante

4 Por ejemplo los trabajos de Adriana Puiggrós, Héctor Rubén Cucuzza, Mariano Narodowski, Juan Carlos Tedesco, Silvia Finocchio.

5 Por ejemplo: Lilia Ana Bertoni, Patriotas, cosmopolitas y nacionalistas. La construcción de la nacionalidad argentina a fines del siglo XIX. (Buenos Aires: Fondo de Cultura Económica, 2001); Lucía Lionetti, La misión politica de la escuela pública. Formar a los ciudadanos de la república (1870-1916). (Buenos Aires: Miño y Dávila, 2007).

6 Carlos Newland, Buenos Aires no es pampa. La educación elemental porteña. 1820-1860. (Buenos Aires: Grupo Editor Latinoamericano, 1992); Carlos Newland, "Enseñanza elemental y superior (18101862)" en Nueva historia de la nación argentina, (2007). Ricardo Levene Historia de la nación Argentina (desde los origenes hasta la organización definitiva en 1862) (Buenos Aires: Planeta. Tomo VI), 261-275; José Bustamante Vismara, Las escuelas de primeras letras en la campaña de Buenos Aires (1800-1860). (La Plata: Asociación Amigos del Archivo Histórico, 2007).

7 Mark Szuchman, Order, family, and community in Buenos Aires.1810-1860 (Stanford: Stanford University Press, 1988). Mark Szuchman "Childhood Education and Politics in Nineteenth-Century Argentina: the Case of Buenos Aires", Hispanic American Historical Rreview. Vol.:70 No. 1 (1990): 109-138. 
la escasa y poco satisfactoria oferta pública ${ }^{8}$. El estudio de estas escuelas permitió observar la integración de los inmigrantes a la sociedad receptora, en tanto espacio en el cual la segunda generación de inmigrantes socializaba e incorporaba prácticas y valores culturales que les permitirían asimilarse o preservar la identidad étnica de los padres. Sin embargo, estos trabajos centraron su atención en el último cuarto del siglo XIX y principios del siglo $\mathrm{XX}$, nada sabemos sobre estos proyectos educativos y sobre las escuelas de extranjeros en la primera mitad del siglo XIX.

En suma, los trabajos disponibles en la actualidad sobre el sistema educativo porteño antes de la Ley de Educación Común son escasos. La historia de la educación ha centrado su atención en el sistema educativo a partir de 1884 y en las escuelas públicas. Los estudios migratorios sólo han indagado sobre las escuelas comunitarias de extranjeros que existían paralelamente a las del Estado durante el último cuarto del siglo XIX y el siglo XX. Y los historiadores que han trabajado sobre el sistema educativo porteño antes de la ley de 1884 no se han detenido a estudiar el desarrollo de las instituciones educativas administradas por extranjeros en particular. No obstante, las escuelas inglesas desempeñaron un papel de gran relevancia en la educación porteña.

El objetivo del presente trabajo es contribuir a complejizar las aproximaciones sobre las escuelas y la educación durante la primera mitad del siglo diecinueve deteniéndonos en el estudio de las escuelas de particulares inglesas. La inestabilidad política, los vaivenes de las políticas educativas, el ingreso incipiente de extranjeros, el quiebre del vínculo con España, las estrechas relaciones comerciales con Gran Bretaña fueron el escenario sobre el cual surgieron y se desarrollaron gran cantidad de escuelas de particulares en manos de ingleses, escoceses, irlandeses y norteamericanos. A lo largo del artículo estudiaremos la inserción de estas escuelas en el sistema educativo porteño, la importancia de la educación para los británicos y las características de las escuelas inglesas, entendiendo por escuelas inglesas y/o angloparlantes a las instituciones educativas dirigidas por ingleses, escoceses, irlandeses y/o norteamericanos o que se promovían como tales.

\section{Presencia británica en Buenos Aires}

Luego de una década de conflictos políticos y enfrentamientos militares, en 1820 la autoridad central radicada en Buenos Aires se disolvió y surgieron

\footnotetext{
Véase el trabajo pionero de, Luigi Favero "Las escuelas de las sociedades italianas en la Argentina (1866-1914)" en La inmigración italiana en la Argentina, (2000); eds. Fernando Devoto y, Gianfausto Rosoli (Buenos Aires: Biblos, 2000).
} 
una pluralidad de centros de poderes débiles e independientes entre sí. En Buenos Aires, esta situación provocó una crisis política, a la salida de la cual comenzó el proceso de construcción del Estado de Buenos Aires. Bajo el gobierno de Martín Rodríguez y su Ministro Rivadavia emergió en Buenos Aires un nuevo poder con un plan de reformas tendientes a "modernizar" las estructuras políticas, el aparato estatal, la milicia y la economía?.

También el nuevo gobierno buscó atraer mano de obra laboriosa desde Europa. Si bien se llevaron adelante diversas medidas (creación de la Comisión de Inmigración, proyectos colonizadores, firma de tratados con naciones europeas), su eficacia fue limitada como consecuencia tanto de la inestabilidad política y violencia de la época como de la falta de experiencia en llevar adelante este tipo de proyectos ${ }^{10}$. Aunque los movimientos migratorios en general no mostraron efectos significativos, sí se registró un movimiento destacado de británicos a la región hacia mediados de la década de 1820. La firma del Tratado de Amistad, Navegación y Libre Comercio con Gran Bretaña, los proyectos colonizadores de los hermanos Roberston y de Beaumont y el incremento de los intereses británicos, dispuestos a aprovechar los nuevos negocios que parecían ofrecer espectaculares ganancias, fomentaron el ingreso de éstos extranjeros. Si bien el porcentaje total de emigrantes hacia la región fue pequeño, hacia principios de la década de 1830 este grupo de extranjeros llegó a representar la primera congregación de europeos en la Ciudad de Buenos Aires ${ }^{11}$.

Sin embargo, el gobierno de Martín Rodríguez cayó pronto como consecuencia de divisiones y disputas internas, una guerra en el interior (debido al intento de organizar un Estado Nacional bajo un Congreso Constituyente) y la guerra en el exterior contra Brasil por el control de la Banda Oriental. Luego de un período de crisis política interna, Juan Manuel de Rosas asumió como gobernador de la provincia de Buenos Aires en 1829, quien retuvo el poder hasta $1852^{12}$.

A partir de la década de 1830 se inició un nuevo ciclo migratorio en el Río de la Plata como consecuencia de una mejora en la situación internacional y un importante crecimiento económico. Las sucesivas guerras (de independencia y

9 Tulio Halperin Donghi, Revolución y Guerra (Buenos Aires: Siglo XXI, 1994); Noemí Goldman, Revolución, república, confederación (1806-1852) (Buenos Aires: Sudamericana, 1998).

10 Fernando Devoto, Historia de la inmigración en la Argentina (Buenos Aires: Sudamericana, 2004); José C. Moya, Primos y extranjeros. La inmigración española en Buenos Aires, 1850-1930 (Buenos Aires: Emecé, 2004).

11 Alina Silveira, "Los británicos en Buenos Aires: movimientos poblacionales, pautas matrimoniales e inserción económica (1800-1850)" (Tesis de Maestría en Universidad de San Andrés, 2008).

12 Halperin Donghi Revolución y, Goldman Revolución, república. 
civiles) habían diezmado la disponibilidad de mano de obra en el mercado de trabajo mientras que el reclutamiento militar al cual estaba sujeta la población nativa daba ventajas a los extranjeros que podían ocupar el lugar dejado por éstos en el mercado laboral cuando eran convocados. Estas condiciones favorables impulsaron el ingreso de españoles, franceses, genoveses, etc. No obstante, el ingreso de británicos no mostró el mismo comportamiento. El fracaso de los proyectos colonizadores de la década de 1820 y de muchas inversiones británicas desalentaron la inmigración de ingleses y escoceses quienes perdieron su lugar como primera congregación de europeos en Buenos Aires ${ }^{13}$.

La hegemonía rosista llegó a su fin en 1852 cuando un ejército comandado por Justo José de Urquiza y apoyado por varias provincias del Interior venció al gobernador en Caseros. A pesar de los intentos de conformar una Confederación que uniera a las provincias del Río de la Plata, Buenos Aires, descontenta con el nuevo orden político, se separó. El territorio quedó dividido en dos: la Confederación Argentina y el Estado de Buenos Aires. La tan anhelada unión debió esperar una década más. Recién en 1862 Buenos Aires se incorporó a la Confederación y comenzó, no sin conflictos, la construcción del estado nacional sobre las bases de la economía agroexportadora (1862-1880) ${ }^{14}$.

Luego de Caseros el proceso migratorio no sufrió grandes transformaciones. A partir de entonces el estado comenzó a tomar un mayor protagonismo fomentando la inmigración. Los sucesivos gobiernos consideraron que la inmigración debía poblar el "desierto" y traer consigo los valores y hábitos que debían ser imitados por los nativos y que permitirían el desarrollo del país. Era importante entonces, fomentar la llegada de individuos procedentes de los países más desarrollados de Europa. ${ }^{15}$ Hacia fines de la década de 1860 un poco más de la mitad de los extranjeros residentes en la ciudad de Buenos Aires eran italianos, seguidos por los españoles y franceses. Los británicos tan sólo representaban el cuatro por ciento del total de los extranjeros para ese momento ${ }^{16}$.

\section{El sistema educativo porteño}

El sistema educativo en Buenos Aires durante buena parte del siglo XIX fue un sistema heterogéneo y descentralizado. En primer lugar, estaban

13 Silveira "Británicos en Buenos Aires".

14 Marta Bonaudo, Liberalismo, Estado y Orden Burgués (1852-1880) (Buenos Aires: Sudamericana, 1999 tomo IV); Tulio Halperin Donghi, Una nación para el desierto argentino (Buenos Aires: CEAL, 1995).

15 Devoto, Historia de la inmigración, Moya, Primos y extranjeros, María Bjerg, Historias de la inmigración en la Argentina. (Buenos Aires: Edhasa, 2009).

16 Archivo General de la Nación (AGN), Buenos Aires-Argentina, Censo Nacional de 1869. 
las escuelas públicas de varones bajo la dirección del Estado mientras que la educación femenina recayó en manos de la Sociedad de Beneficencia, institución administrada por mujeres destacadas de la sociedad criolla y sostenida económicamente por el estado y aportes voluntarios.

En segundo lugar, estaban las escuelas de particulares laicas, en manos de privados nativos y/o extranjeros, que no recibían ningún tipo de subvención estatal, se financiaban a través de las cuotas que pagaban los alumnos y no tenían necesariamente una orientación religiosa, aunque muchas veces incluían en su currículo escolar la materia religión. Este mundo educativo era muy heterogéneo. Los mejores establecimientos, denominados colegios o liceos, eran institutos exclusivos para varones donde se brindaba educación elemental y media. Éstos convivían con escuelas más pequeñas compuestas por un docente y un ayudante que impartían lecciones en una habitación de una casa.

En tercer lugar, estaban las escuelas elementales sostenidas por las iglesias o fundadas como asociaciones voluntarias. Los conventos ofrecían educación gratuita, católica y orientaba sus esfuerzos a los niños más humildes (principalmente mulatos y mestizos) ${ }^{17}$. Por su parte, las iglesias protestantes a partir de la década de 1820 cuando se instalaron en Buenos Aires, también fundaron escuelas propias donde se enseñaba la religión y el idioma de la nacionalidad de origen. A su vez, las comunidades de inmigrantes ofrecían educación a los miembros de su congregación donde muchas veces se buscaba preservar y re construir una identidad étnica entre los hijos de los inmigrantes.

Por último, algunos niños se educaban por fuera de las instituciones escolares, ya fuera con un tutor (muchas veces de origen extranjero) o con algún miembro de la familia. Sin embargo, contratar un maestro particular era caro, por lo que sólo los más ricos podían brindar este tipo de educación no formal a sus hijos.

En cuanto a las escuelas de particulares, durante el período rivadaviano experimentaron un gran desarrollo. El clima de mayores libertades que generaron las reformas de Rivadavia brindó a las instituciones privadas una autonomía bastante amplia para organizarse, adoptar métodos de enseñanza y elegir la currículo. Esta situación sumada a la creciente población británica, estadounidense y francesa fomentó el surgimiento de éstos colegios donde se enseñaba además de los contenidos básicos de una instrucción elemental

17 Las escuelas conventuales desaparecieron en 1820 luego de la clausura de los conventos y volvieron a surgir en la década de 1850. 
(lectura, escritura y aritmética) la propia lengua y religión (en especial para los protestantes). A su vez, la estrecha vinculación comercial con Inglaterra se hizo sentir en el sistema educativo. Después de 1825 muchas instituciones ofrecían una orientación comercial con la enseñanza de contabilidad, aritmética mercantil e inglés.

La cantidad de escuelas privadas aumentó a la par de las escuelas públicas en la década de 1820. No obstante, los establecimientos de iniciativa particular fueron mucho más numerosos que los del estado y concentraron un importante caudal de alumnos. Para 1824 había 95 escuelas en la ciudad de Buenos Aires, 80 eran privadas y sólo 15 públicas. Estas escuelas recibían unos 4.100 niños, los cuales representaban el 60\% de población escolar ${ }^{18}$. Si bien el estado había intentado aumentar su participación en el sistema educativo local durante el gobierno de Martín Rodríguez, la mayoría de los niños eran educados en instituciones privadas.

Estos colegios continuaron floreciendo bajo los gobiernos de Rosas como consecuencia del arancelamiento de las escuelas estatales ${ }^{19}$. Muchos docentes que trabajaban en colegios públicos, pasaron a los de particulares, los cuales pudieron subsistir porque ofrecían sus servicios a sectores de clase media y media alta que podían afrontar el gasto mensual que implicaba la cuota escolar. A su vez, el aumento de la presencia extranjera en Buenos Aires fomentó la instalación de colegios para los hijos de extranjeros. Como consecuencia, la cantidad de escuelas de particulares creció ampliamente; en 1846,125 a los cuales asistían 6.700 alumnos $^{20}$.

Sin embargo, las libertades de las cuales gozaron las escuelas bajo el período rivadaviano llegaron a su fin con Rosas. Dos decretos intentaron aumentar el control estatal sobre las mismas. El primer de éstos se emitió en 1831 y establecía que todos los establecimientos privados debían solicitar un permiso al inspector escolar para abrir sus puertas y presentar justificaciones necesarias sobre su moralidad, religión y suficiencia. Aquellos colegios cuyos docentes no acreditaran moralidad suficiente o no fueran católicos o en los cuales no se destinara los sábados a la enseñanza del dogma católico serían clausurados. Rosas veía con malos ojos el crecimiento de las escuelas en

\footnotetext{
18 Newland, Buenos Aires no es pampa.

19 A partir de la década de 1830 como consecuencia del ajuste de cuentas públicas se restringió y luego eliminó el financiamiento de las escuelas del estado.

20 Newland, Buenos Aires no es pampa; Antonio Salvadores, "El decreto del 26 de mayo de 1844, sobre las escuelas de la provincia de Buenos Aires". Boletin del Instituto de Investigaciones Históricas. Vol: VIII No 39 (1929): 41-63; Antonio Salvadores, La instrucción primaria desde 1810 hasta la sanción de la ley 1420 (Buenos Aires: Talleres Gráficos, Consejo Nacional de Educación, 1941).
} 
manos de extranjeros protestantes, las cuales se habían desarrollado ante la escasez de maestros católicos y eran sospechados de aprovechar su éxito para difundir su idioma y culto.

En 1844 un nuevo decreto reforzó la norma anterior y el Ministerio de Gobierno se hizo cargo directamente de hacer cumplir la norma que hasta ese momento los funcionarios públicos poco habían hecho para que se respetara. El decreto establecía que las escuelas debían solicitar un permiso para abrir sus puertas y renovar anualmente la autorización para su institución. El decreto también establecía que los extranjeros no podían enseñarle a los niños nativos, por lo cual si querían continuar desempeñándose en sus funciones debían naturalizarse. Muchos maestros españoles se nacionalizaron para poder continuar en sus funciones; sin embargo pocos ingleses lo hicieron porque el tratado de 1825 los protegía por lo cual no les convenía renunciar a su nacionalidad y con ello a la protección del consulado inglés. A su vez, se reiteró la prohibición de que maestros protestantes enseñasen a niños católicos.

Si bien los decretos parecían en teoría bastante restrictivos, en la práctica, no sólo hubo escaso control sino que además se hicieron varias excepciones para permitir a las escuelas de extranjeros continuar funcionando. Probablemente, ante la escasez de maestros locales y la superior preparación de los docentes extranjeros fuera difícil prescindir de ellos. Por otro lado, con la suspensión del financiamiento de las escuelas estatales, fue inevitable el desarrollo y florecimiento de los establecimientos de particulares. A su vez, las escuelas de extranjeros protestantes se les permitió continuar funcionando sin nacionalizarse ni enseñar el dogma católico, si limitaban el ingreso a niños de su misma fe religiosa ${ }^{21}$.

Con la caída de Rosas, se anularon los decretos restrictivos del período anterior y se volvió a un período de mayor libertad para las escuelas de particulares. Sin embargo, la introducción nuevamente de escuelas públicas y gratuitas afectó directamente a los establecimientos privados, en especial los más pequeños que habían surgido cuando los colegios del estado dejaron de ser financiadas por el erario público. Si bien la educación privada sufrió inicialmente el impacto de la creación de escuelas estatales gratuitas y muchas debieron cerrar (en 1846 había 127 y en 1856 más de la mitad ya no estaban en funcionamiento), una vez que el aumento de aquellas se estabilizó, el sector privado se recuperó velozmente. Escuelas nuevas emergieron a la par del crecimiento de la población como consecuencia de la inmigración, del

21 Newland, Buenos Aires no es pampa, Salvadores. 
crecimiento económico del período y de la amplia libertad que se les otorgó. Para 1860 había 139 escuelas privadas a las cuales asistían 6.400 niños, aunque el número debió ser mayor porque se carecía de la cantidad de funcionarios necesarios para llevar adelante un buen relevamiento y además muchos maestros eran reacios a brindar información. Para 1870 había 160 colegios particulares a los cuales concurrían 9.000 alumnos $^{22}$.

El desarrollo de las escuelas públicas y privadas se vio reflejado en la alfabetización de la población local. Durante la primera mitad del siglo diecinueve, según ha estudiado Newland, se dio una paulatina evolución positiva en la instrucción de la población ${ }^{23}$. Para 1855 cerca del $47 \%$ de la población porteña sabía leer (sin grandes diferencias entre mujeres y varones, $46 \%$ para las primeras y $48 \%$ para los segundos $)^{24}$.

En 1872 la cantidad de escuelas en la ciudad de Buenos Aires había llegado a 237 (130 públicas y 107 privadas) ${ }^{25}$. Más de la mitad de éstos establecimientos eran de ambos sexos (la mitad restante se dividía entre colegios sólo para varones y sólo para mujeres $)^{26}$. Sin embargo, el $60 \%$ de la población escolar de los colegios públicos eran niñas. En los institutos particulares, la relación se invertía (61\% eran varones y 39\% mujeres). ¿Cómo se reflejó esta situación en la alfabetización de la población porteña? A pesar de la importante presencia de niñas en las escuelas del Estado, en las décadas de 1860 y 1880 los índices de alfabetización masculina fueron más elevados que los femeninos ${ }^{27}$. En cuanto a la enseñanza recibida por sexo, ambos eran instruidos por igual en asignaturas esenciales como lectura, escritura, aritmética y lengua castellana. Sin embargo, algunas disciplinadas eran exclusivas para varones (como geometría, álgebra, ciencias naturales y latín) y otras específicas de las niñas

22 Newland, Buenos Aires no es pampa, 189; Juan P. Ramos, Historia de la instrucción primaria en la república Argentina 1810-1910 (Atlas escolar) (Buenos Aires: Peuser, 1910).

23 Newland, Buenos Aires no es pampa.

24 Las escuelas de niñas de la Sociedad de Beneficencia habían extendido ampliamente la educación entre las niñas durante la primera mitad del siglo XIX. Véase: Lucía Lionetti, "Continuidades y discontinuidades de las políticas públicas en la educación de las 'madres de ciudadanos' en la Argentina del siglo XIX" en Educación, género y ciudadania. Las mujeres argentinas: 1700-1943. Editado por Pilar Pérez Cantó y Susana Bandieri (Buenos Aires: Miño y Dávila, 2005).

25 AGN, Buenos Aires-Argentina, Censo de la Educación de la República Argentina de 1872 (las características del censo son analizadas más adelante).

2628 de las 107 escuelas públicas eran de varones y 23 de mujeres. En el caso de las particulares, de las 130, 47 eran para niños y tan sólo 13 sólo para niñas. AGN, Buenos Aires-Argentina, Censo de la Educación de la República Argentina de 1872.

27 Según el censo nacional de 1869 el $67 \%$ de los varones residentes en la ciudad de Buenos Aires sabían leer y escribir frente a tan sólo el $47 \%$ de las mujeres. Esta brecha, no obstante, se acortó en la década de 1880. Según el censo municipal de 1887 la alfabetización masculina era del $87 \%$ y la femenina del 81\%, aunque en ambos casos la brecha fue mayor a la de 1855. (AGN, Buenos AiresArgentina, Censo Nacional 1869 y Censo Municipal 1887). 
(labores de mano, canto, música instrumental), situación similar a la registrada en la totalidad de los públicos (aunque en éstos ciertas asignaturas como álgebra, química y latín no eran enseñadas). En relación a la edad de los niños escolarizados, más del 80\% (tanto en las escuelas públicas como particulares) de los alumnos tenían entre 5 y 15 años. En las escuelas del estado la mayor escolarización femenina fue constante, en todas las franjas etarias. En el único momento en que la presencia de varones y mujeres se equilibró fue entre los mayores de 15 (quienes sólo representaban menos del tres por ciento del total de alumnos). Por el contrario, en los colegios privados sólo entre los menores de cinco años la preponderancia masculina en las escuelas cedió paso a la femenina (el 61\% eran niñas).

Si bien el objetivo del presente trabajo no es indagar sobre las diferencias de género en la educación y alfabetización porteña, llama la atención las diferencias encontradas en la escolarización de niños y niñas en las escuelas públicas y de particulares así como el aumento de la brecha de los índices de alfabetización masculina y femenina en las décadas de 1860 y 1880 en relación a 1855. Los niños que asistían a los colegios de particulares provenían de familias de cierto poder adquisitivo; sus padres no sólo podían enviar a sus hijos al colegio, prescindiendo de éstos como mano de obra familiar, sino que también tienen los suficientes recursos para dedicar una parte del presupuesto familiar al pago de su educación. Probablemente esta mejor posición económica les permitió enviar a sus hijos al colegio y que éstos permanecieran durante varios años en él, retardando su inserción al mercado laboral. Por el contrario, quienes enviaron a sus hijos a los colegios públicos disponían de menores recursos, por lo cual la presencia de los hijos varones en el sistema escolar implicaba un menor ingreso familiar. Los varones, en cuanto tenían edad suficiente para ingresar al mercado de trabajo eran retirados de las escuelas, en especial en un contexto en el cual la posibilidad de leer y escribir por sí mismas no repercutían directamente en la posibilidad de conseguir un empleo mejor remunerado, dado el elevado porcentaje de alfabetización de la población local ${ }^{28}$. La hija mujer, por el contrario, podía continuar concurriendo al colegio, tal vez las tareas domésticas fueran más compatibles con la escolarización que los trabajos masculinos. Por otro lado, dado que las labores esperadas de las mujeres (costura, bordado, labores de mano, música, dibujo, etc.) eran en muchos casos parte del currículo escolar para la educación de las niñas, su escolarización estaba asociada a que aquello que aprenderían sería útil para la gestión doméstica y la vida social esperable de ellas así como para el ejercicio de trabajos derivados de esos conocimientos. A su vez, el incremento en la brecha de alfabetización entre hombres y mujeres

28 Newland, Buenos Aires no es pampa. 
puede deberse a que durante la segunda mitad del siglo diecinueve se haya priorizado, en la educación de las niñas, la enseñanza de labores manuales por sobre la lectura y la escritura. Esto nos lleva a plantearnos otro problema, ajeno al presente trabajo: la diferencia en el contenido de la enseñanza femenina y masculina y sus efectos en su posible inserción ocupacional ${ }^{29}$. En suma, nuestra aproximación al problema de la educación y el género es tan sólo descriptiva; llamamos la atención hacia la necesidad de realizar mayores estudios al respecto para elaborar una interpretación más compleja y sólida sobre la diferencial escolarización de niños y niñas en la ciudad de Buenos Aires.

\section{La educación para los británicos}

A partir de la década de 1820, como vimos, el creciente ingreso de ingleses, escoceses, irlandeses y norteamericanos a Buenos Aires así como la política de mayor libertad de enseñanza de Rivadavia fomentó el surgimiento de escuelas de particulares, entre ellas estaban las de ingleses donde se enseñaban los contenidos básicos de una instrucción elemental -lectura, escritura y aritmética- así como el inglés.

Las condiciones pre-migratorias influyeron en el desarrollo de éstos emprendimientos. Como protestantes éstos extranjeros se preocuparon por establecer un sistema educativo donde las nuevas generaciones pudieran recibir una educación elemental similar a la de sus patrias de origen. En Inglaterra y Escocia, como consecuencia de la reforma protestante, se desarrolló tempranamente un sistema educativo cuyo objetivo era que los nuevos fieles se familiarizaran con la Biblia. A su vez, según afirma Stone, la lucha entre anglicanos y disidentes por convertir a la clase baja motivó el desarrollo de un sistema educativo popular ${ }^{30}$. Posteriormente, hacia fines del siglo XVIII y durante el siglo XIX se produjo una nueva expansión del sistema educativo y de las tasas de alfabetización en Inglaterra y Escocia ${ }^{31}$. Como consecuencia los británicos que emigraron tenían una amplia experiencia educativa, estaban acostumbrados a recibir algún tipo de instrucción si bien no fuera elemental.

29 Algunas aproximaciones a la problemática pueden verse en: Pérez Cantó y Bandieri Educación, género y ciudadanía.

30 La educación fue tomada por los disidentes y los metodistas como medio para difundir sus ideas religiosas y conquistar fieles; ante esta situación los anglicanos fueron arrastrados y estimulados a imitar este modelo y fomentar y difundir un cierto grado de educación entre las clases pobres. Lawrence Stone, "Literacy and Education in England, 1640-1900" en Past \& Present No 42, (1969): 69-139.

31 Para el 1900 las tasas de alfabetización eran del 98\% en Escocia y del 97\% en Inglaterra y Gales. Stone, "Literacy and Education". 
Existían diversos tipos de establecimientos donde los británicos podían recibir algún grado de instrucción en la madre patria. Por un lado, estaban las escuelas dominicales, muy establecidas en las congregaciones puritanas y evangélicas, donde se enseñaba principalmente la lectura de la Biblia, aunque algunas también brindaban instrucción en escritura y aritmética. Este tipo de escuelas contaban con la ventaja de encajar fácilmente en la rutina laboral de la clase trabajadora y no significaban un gasto extraordinario: no requerían un edificio especial ni maestros pagos y no necesitaban un capital inicial para fundarse. Por otro lado, estaban las escuelas diarias entre las cuales se destacaban las denominadas grammar schools que dependían de la Iglesia Oficial Anglicana. Allí se enseñaba latín, griego, inglés, aritmética y escritura. Por su parte, los protestantes no conformistas, excluidos de estas escuelas, crearon sus propios establecimientos educativos, donde, además de una educación elemental, ofrecían otras materias como idiomas modernos, literatura, matemática y ciencias naturales. Estos emprendimientos eran solventados por medio de donaciones, suscripciones voluntarias y cuotas pagadas por los padres (que eran de unos 2 a 5 pence por semana). También éstos colegios contaban con el apoyo económico del terrateniente residente en la región así como del clero. No obstante, éstas no satisfacían las expectativas de aquellos que pretendían algo más que las habilidades básicas. Para ellos estaban las denominadas public schools, instituciones educativas inglesas de alta distinción, de las cuales las clases trabajadoras en su mayoría quedaban excluidas ${ }^{32}$.

De este modo, las condiciones pre-migratorias influyeron en el deseo de estos extranjeros por desarrollar rápidamente escuelas que satisficieran sus necesidades educativas. No obstante, no todos tenían en mente un mismo modelo. Por un lado, los párrocos de las respectivas iglesias étnicas temían por el futuro de los más pequeños al ser educados en un país católico; por ello a través de diversos medios procuraron que éstos recibieran una instrucción elemental que les permitiera ser buenos fieles según las pautas y normas de la propia religión. Los padres de familia, por su parte, en general, sólo demandaban una educación similar a la que habían recibido en sus patrias de origen.

El futuro de las nuevas generaciones de británicos que crecían en el país consternó a algunos, quienes alzaron su voz públicamente a través de la prensa. En el periódico inglés British Packet entre mayo y julio de 1834 aparecieron una conjunto de notas firmados por "Benevolus", donde un escritor anónimo resaltaba la importancia de la educación de los jóvenes,

32 Sobre la educación el Inglaterra y Escocia véase: Stone, "Literacy and Education; Gillian Sutherland, "Education" en The Cambridge Social History of Britain 1750-1950. Social Agencies and institutions editado por F. M. L. Thompson (Cambridge: Cambridge University Press, 1996 Vol. 3). 
dado que en ella residía el futuro de la sociedad, era la base de la religión, la felicidad y la libertad civil. Sin embargo, en Buenos Aires esta prioridad no estaba siendo ponderada. Los extranjeros en Buenos Aires eran "indolentes ante la necesidad de ofrecer a los más pequeños una educación que les permitiera afrontar el desafío de la vida con el éxito, el honor y las ventajas que les brindaría la educación".

The cause of Juvenile Education, in point of importance, is second to none. It is the source of all that is great and honourable; the basis of true and rational religion; the centre of social happiness, and the cement of civil liberty. It fits a man for acting his part in the great drama of life with success, honor, and advantage (...) The cause advances slowly, not that its enemies are powerful, but because its friends are indolent $t^{33}$.

A su vez, "Benevolus" expresaba su preocupación ante la gran cantidad de niños "ignorantes, desaliñados, bulliciosos, abandonados" que deambulaban por las calles sin ocupación útil alguna. El trasplante migratorio había quebrado la unidad de los extranjeros y muchos valores presentes en los países de origen habían desaparecido. En la aventura inmigratoria los hombres se habían vuelto egoístas e individualistas. En esta situación muchos habían descuidado sus deberes sociales y familiares zambulléndose en la intemperancia y el libertinaje. Los culpables de esta situación, concluía, eran los padres, quienes no se ocupaban de instruir a sus hijos ni de apoyar aquellas instituciones que se encargaban de la instrucción de los menores. La principal preocupación era el futuro de todos aquellos hijos de extranjeros que crecían en estas condiciones:

"(...) A variety of causes have conspired in producing this deplorable result. Among these, the heterogeneous elements of which our foreign society is composed, may be mentioned as one of the most prominent. Men of the most opposite views and principles, from all quarters of the world, are blended together in one chaotic mass. The restraint of relationship and neighborhood, the almost instinctive influence of habit and custom, and that salutary deference to public opinions which operate so extensively and so benignly in long established and well regulated societies, are here wholly unknown. Broken and severed in the rude act of transplantation, these secret but powerful auxiliaries of virtue, order, and patriotism, have ceased for ever. Released from their artificial restraints, the Emigrant, in too many cases, becomes a reckless adventurer; responsible only to those upon whom he is immediately dependant in his daily avocation, and utterly regardless to every consideration of character and reputation. In such circumstances, it is to be expected that many will become remiss in the discharge of their social and relative duties; and that others will plunge, as we daily see them, into all the excesses of intemperance and

33 British Packet 10/5/1834 p. 2.

Rev. hist.edu.latinoam - Vol. 14 No. 18, enero - junio 2012 - ISSN: 0122-7238 - pp. 183 - 210 
licentiousness... They bequeath to the world, in their hapless offspring, a legacy of ignorance and worthlessness, that must be removed and corrected by others, unless they are prepared to hazard the many future evil consequences that will infallibly result from them... Here, then, is the prolific source of evil; the culpable apathy, and the still more culpable irreligion and immorality of Parents..." "34

Sin embargo, la visión de este individuo no fue la única que circuló por la prensa angloparlante. Por el contrario, otros sujetos resaltaron las virtudes y éxitos alcanzados en educar a los niños de habla inglesa por diversos colegios angloparlantes en el período. Por ejemplo, fueron continuos los elogios a algunos colegios dirigidos por británicos provenientes de diversas personas involucradas en la educación de los niños angloparlantes (padres de alumnos, angloparlantes respetados, etc.). Públicamente expresaron su satisfacción por los avances alcanzados en los colegios y resaltaron el espíritu e inteligencia de los niños y su continuo progreso. La imagen de los niños era completamente opuesta a la de Benevolus: mientras que el último los describía como "ignorantes, desaliñados, bulliciosos, abandonados" otras persona los encontraba "neat, healthy, cheerful lads, who went through the various exercises of the day with a self-possession, accuracy, and precision, that met with the unqualified approbation of the numerous and respectable attendance" 35 .

¿Por qué entonces esta visión negativa sobre la segunda generación de angloparlantes, su futuro en la sociedad y el estado de las escuelas inglesas? Como veremos, las escuelas regenteadas por ingleses, escoceses, norteamericanos e irlandeses parecían estar desarrollándose exitosamente con gran cantidad de alumnos ante una competencia que tendía a crecer, diversificarse y complejizarse con el paso del tiempo. ¿Por qué entonces el enfado de este sujeto? ¿Por qué alzar la voz públicamente para llamar la atención sobre la educación juvenil? Este tipo de discurso fue frecuente entre los líderes étnicos de otras comunidades de extranjeros, e incluso el mismo reclamo, como ha estudiado Seiguer, se encuentra entre los ingleses a principios del siglo $\mathrm{XX}^{36}$. Probablemente el reclamo no fuera por la calidad de la enseñanza que estaban recibiendo éstos niños ni por la escasez de escuelas. La insatisfacción de Benevolus pareciera haber estado vinculada a un deseo por conformar una comunidad étnica por medio de la educación entre los inmigrantes. De ahí su constante reclamo por la pérdida de valores de la madre patria y el individualismo de los compatriotas. La instrucción de los

British Packet 17/5/1834, 2 y 3.

British Packet, 3/1/1835.

36 Véase: Paula Seiguer, "La iglesia anglicana en la Argentina y la colectividad inglesa. Identidad y estrategias misionales, 1869-1930" (Tesis de Doctorado en Universidad de Buenos Aires, 2009). 
jóvenes le brindaría a la población angloparlante un elemento de cohesión dado que permitiría inculcar los valores, hábitos y principios religiosos de la madre patria y sobre éstos se construiría la comunidad angloparlante.

Había una cantidad significativa de colegios angloparlantes, muchos de ellos a cargo de individuos de gran capacidad y prestigio como veremos. No obstante, el malestar de Benevolus provenía de que la mayoría de estas escuelas no buscaban educar a los niños "étnicamente". Mientras que este tipo de colegios se multiplicaban, los primeros intentos por construir emprendimientos educativos étnicos, como veremos, fracasaban ante la escasez de alumnos y recursos. La falta de interés por parte de los padres y de los extranjeros en general y la demanda de una mejora en la calidad educativa no se referían a las escuelas de particulares, su reclamo apuntaba a la falta de apoyo a los colegios étnicos. En especial, la crítica provenía del "peligro" que muchos hijos de ingleses y escoceses enfrentaban al no poder acceder a las costosas escuelas particulares angloparlantes. Si no accedían a éstos colegios y no se apoyaban los emprendimientos educativos comunitarios de bajo costo entonces éstos terminarían asimilándose a la sociedad receptora y perderían así los valores culturales y morales de la madre patria.

\section{Las escuelas inglesas de particulares en Buenos Aires}

Entre 1820 y 1860 se desarrollaron en la ciudad de Buenos Aires gran cantidad de escuelas particulares inglesas. A través de los avisos publicados en el British Packet, informes de la policía y permisos otorgados según el decreto de Rosas de 1844 hemos podido reconstruir un listado de colegios que funcionaron en Buenos Aires entre 1820 y 1860. En éstos cuarenta años hubo en la ciudad unos cuarenta colegios (aunque no todos funcionaron en el mismo momento) dirigidos por ingleses, escoceses, irlandeses y norteamericanos. ${ }^{37}$ Éstos establecimientos brindaban a los niños una instrucción variada muy similar a la ofrecida por otros colegios de particulares, aunque en estas últimas la instrucción religiosa tenía un peso mayor, lo cual es esperable dadas las circunstancias locales que limitaban las escuelas de protestantes y la difusión de dicha fe (cuadro A). Por otro lado, los colegios ingleses tenían una marcada orientación comercial (en la mayoría se enseñaba aritmética mercantil y teneduría de libros), mayor que en las escuelas de otros particulares.

Las lecciones en muchos de éstos colegios incluían la enseñanza del español. Se consideraba que era importante que los niños aprendieran a hablar

37 British Packet, AGN Sala X: 33-4-9, Libro 138, 33-5-10 Libro 164; 33-5-6 Libro 154; 33-6-1 Libro 168; 33-6-2 Libro 170. 
el idioma local correctamente para poder insertarse económica y socialmente en la sociedad local, en especial considerando que las tasas de retorno en el período eran más bien bajas. El aprendizaje de la lengua nativa era esencial porque la mayoría de éstos extranjeros se quedarían en la región, dado que las probabilidades de regresar a la madre patria eran escasas. ${ }^{38} \mathrm{La}$ introducción de la enseñanza del español en las escuelas inglesas fue bien recibida. Por ejemplo, un padre angloparlante dejaba asentado públicamente en el periódico inglés British Packet la importancia de que los niños angloparlantes aprendieran tanto la lengua de sus progenitores como la del país que los acogía. Si bien a través del contacto diario con los nativos se podía adquirir el idioma local, era importante que el español fuera enseñado en las escuelas para que los niños aprendieran a hablarlo correctamente. A su vez, el aprendizaje del español les facilitaría a los niños una mejor inserción en el país:

In regard to the more advanced boys, this was certainly wanted. The children of foreigner born and brought up here, must naturally, along with the language of their parents, speak that of the country; but without care and instruction they will not do it correctly. Their views and prospects are all connected with this country, -their chief intercourse in the prosecution of their future plan and avocation, must inevitably be with its native in habitants; and the better they can speak their language, they are so far better qualified to act their part with respectability and advantage $e^{39}$.

Muchos de estas escuelas estaban en manos de ingleses o hijos de ingleses y se concentraban en los alrededores de la plaza Victoria (hoy Plaza de Mayo). Esta distribución se debió a que allí era donde se concentraba la mayoría de la población. Según el censo municipal de 1855, el 30\% de la población de la ciudad habitaba en las parroquias céntricas de Catedral al Sud, Catedral al Norte y San Miguel. Consecuentemente, el 30\% de la población escolar también estaba asentada en dicha zona, el $40 \%$ de las escuelas y cerca del $60 \%$ de los maestros ${ }^{40}$.

Algunos de éstos colegios tuvieron una presencia destacada entre la población angloparlante así como en la sociedad local. Tal es el caso de la escuela del inglés Henry Bradish. Este había estudiado en Liverpool donde se inició en la carrera eclesiástica, aunque luego la abandonó. Su colegio (Academia Literaria Comercial, luego Academia Clásica Comercial, y más tarde Academia Comercial Inglesa o Foreign Mercantil Academy) fue muy reconocido en el período; concurrieron a él los hijos de personajes destacados, como los

\footnotetext{
38 Hasta avanzado el siglo XIX el viaje en barco a través del océano Atlántico era largo y traumático, las comodidades de los barcos mínimas y los costos elevados.

39 British Packet 26/9/1835 pp. 2 y 3.

40 AGN, Buenos Aires-Argentina, Registro Estadístico del Estado de Buenos Aires, 1856.
} 
niños del Almirante Brown, de Carlos Ezcurra, de José Antonio Wilde ${ }^{41}$. El establecimiento del inglés Percy Lewis, Colegio de la Independencia, fundado en 1833 con el apoyo de varias familias criollas, también cobró relevancia localmente brindando educación a los nativos. Por su colegio pasaron figuras tales como Prilidiano Pueyrredón, Palemón y Eliseo Huergo y Adolfo Arriola ${ }^{42}$.

La escuela de la inglesa Elizabeth Hyne, que funcionó entre 1822 y 1834, fue otra de las cuales resaltaron en el escenario educativo local. El colegio de Mrs. Hyne, quien había realizado sus estudios en Inglaterra, fue muy conocido y respetado y una gran cantidad de padres mandaron a sus hijos allí, llegando a contar con unos 80 niños ${ }^{43}$. Ya en 1825 un inglés observaba: "Entre los numerosos colegios existe uno dirigido por una señora inglesa, Mrs. Hyne, que disfruta del favor del público; cuenta con setenta alumnos a los que se les enseña con otras cosas indispensables el idioma inglés" ${ }^{\prime 4}$. Cuando Mrs. Hayne regresó a Inglaterra el British Packet comentó con gran pesar su partida y resaltó su labor educativa difundiendo el inglés entre las familias locales ${ }^{45}$.

Gilbert Ramsay, quien estudió en la Universidad de Glasgow, fue otro de los educadores angloparlantes que cobró notoriedad localmente. Inicialmente la Academia Argentina (luego Commercial Academy) buscó brindar educación elemental a los hijos de extranjeros angloparlantes, pero, como la instrucción impartida en él ganó prestigio, muchos niños criollos también concurrieron a la escuela, en especial porque se enseñaba el español así como el inglés y no se instruía en religión (muy importante para los niños criollos católicos que quisieran asistir a los colegios regenteados por protestantes). En 1835 asistían al colegio unos 60 niños. Varios padres y miembros destacados de la comunidad angloparlante resaltaron la enseñanza impartida en el colegio. Por ejemplo, en 1835 una persona que había asistido a los exámenes públicos de la Commercial Academy hacía pública su satisfacción por los resultados educativos alcanzados en la institución y felicitando a Ramsay por los éxitos de su labor educativo alcanzados en tan escaso tiempo ${ }^{46}$. También los padres que enviaban a sus hijos al colegio resaltaron el progreso alcanzado por los niños; elogiaron el colegio y la figura de Ramsay como educador; y destacaron

${ }_{41}$ Salvadores, La instrucción primaria; José Antonio Wilde, Buenos Aires desde setenta años atrás (Buenos Aires: Eudeba, 1960); Maxine Hanon, Diccionario de británicos en Buenos Aires (Buenos Aires: Gutten Press, 2005); British Packet, 9/8/1834.

42 Hanon, Diccionario de, Newland, Buenos Aires no es pampa.

43 Wilde, Buenos Aires desde.

44 Un inglés. Cinco años en Buenos Aires, 1820-1825 (Buenos Aires: Solar/Hachette. 1962: 117).

45 British Packet, 30/04/1842.

46 British Packet, 3/1/1835. 
la importancia de un colegio así para la comunidad angloparlante residente en Buenos Aires y para las nuevas generaciones ${ }^{47}$.

A éstos colegios concurrieron una cantidad diversa de niños. Hemos podido reconstruir el universo estudiantil de seis colegios (Colegio de la Independencia de Percy Lewis, Commercial Academy de Ramsay y las escuelas de Ana Bevans, Elizabeth Heathfield, Rosa Wilde de Barton y Catalina Wilson) a través de diversas fuentes. Para la academia de Ramsay y el colegio de Percy Lewis hemos utilizado un listado de alumnos destacados (aquellos que ganaron algún premio) de los años 1836 y 1837 para el primero y 1834 para el segundo publicados en el British Packet. Para los otros colegios hemos encontrado un listado de alumnos realizado por la policía entre 1848 y 1849 como consecuencia del control que se ejercía sobre dichas escuelas (en particular a partir del decreto de 1844) dado que los extranjeros protestantes tenían prohibido educar a niños naturales del país y/o católicos. De éstos datos surge que sólo cerca del $40 \%$ de los niños que asistieron a éstos colegios provenían de familias angloparlantes, quienes eran en su mayoría escoceses e ingleses; el resto eran nativos o de otros orígenes nacionales ${ }^{48}$. Es probable, no obstante que la cantidad de ingleses y escoceses esté sub-representada como consecuencia de la naturaleza fragmentaria de las fuentes utilizadas. Los registros policiales centraron su atención en los colegios que eran vistos como problemáticos por el gobierno: las escuelas protestantes a las cuales concurrían nativos y/o católicos. Si tomamos sólo los datos de los colegios de Ramsay y Lewis el porcentaje de alumnos de origen inglés crece pero la diferencia no es muy elevada (pasa del 40\% al 52,87\%). Sí disminuye significativamente la presencia de niños no ingleses (del 50\% al 26,44\%). En suma, si bien no podemos concluir que a todos los colegios angloparlantes asistían mayoritariamente niños locales dadas las limitaciones de nuestras fuentes, sí podemos suponer que muchos de éstos colegios, algunos en mayor medida que otros, contaron entre sus estudiantes tanto a niños de familias inglesas y escocesas como alumnos de otras nacionalidades y nativos.

47 "I beg, in justice to him, and with your permission, to express my high admiration of the rich treat which he provided for his visitors on the occasion. No one, I am sure, could witness such a number of fine boys enjoying the benefit of Mr. Ramsay's superior tuition, without gratification. It required only to be present to be convinced of the high importance of his Institution to he foreign population of this city. Let him but persevere in his present career, and he will assuredly prove one of the greatest benefactor to his countrymen here. His skilful and successful method of instruction, must eventually manifest itself in the improved character and fortunes of many of the rising generation..." British Packet, 26/9/1835.

48 AGN, Buenos Aires-Argentina, Sala X: 33-6-2 Libro 170 y 33-5-10 Libro 164, British Packet: 8/11/1834, 2/1/1836, 25/3/1837. British Packet. 8/11/1834, 2/1/1836, 25/3/1837. 
Caído Rosas y con él las restricciones a las escuelas protestantes y de extranjeros el escenario educativo angloparlante continuó creciendo y complejizándose. Según el Censo Nacional de Escuelas de 1872 había en la ciudad de Buenos Aires unas 131 escuelas de particulares, entre las cuales sólo unas 20 eran inglesas ${ }^{49}$. La educación impartida en la mayoría de éstos institutos incluía lecciones de lectura, escritura, aritmética, dibujo, geografía, historia, castellano, francés, música instrumental y labores de mano (sólo para las mujeres) (cuadro B). En comparación con las materias enseñadas en el período anterior y en las escuelas de otros particulares del momento, la educación ofrecida por los colegios ingleses era más completa y variada. A su vez, la instrucción de sus alumnos era superior a la del promedio de las escuelas particulares de 1872 (cuadro C). Los colegios ingleses también estaban mejor equipadas; la mayoría contaba con mapas, muestras de dibujo, reloj, tablero contador, pizarras murales, bibliotecas (cuadro D). Eran, a su vez, más espaciosas con capacidad para mayor cantidad de alumnos y tenían mejor infraestructura en general (ventilación, jardines, patios, árboles, bancos, mapas, láminas, libros, etc.). No obstante, no todas las escuelas inglesas tenían las mismas dimensiones. El valor de la propiedad en la cual estaba asentado los establecimientos variaba desde los $\$ 100.000 \mathrm{~m} / \mathrm{c}$ los más chicos (por ejemplo el seminario inglés de señoritas de Byrne, el colegio anglo porteño de Froggatto el colegio inglés de señoritas de MacKen o el de Scott) a más de un millón de pesos moneda corriente los colegios más grandes e importantes como los de George Ryan, de W. D. Junor, o de Robert Bird. Asistían en total unos 1.521 niños a éstos colegios (con una asistencia promedio anual de 859) quienes en su mayoría tenían entre 5 y 15 años. Los colegios estaban principalmente en manos de hombres y mujeres ingleses, escoceses, irlandeses y norteamericanos (muchos de los que figuraban como argentinos eran segunda o tercera generación) aunque el cuerpo de docentes auxiliares era más heterogéneo.

Sin embargo, los datos de los censos no son completos. Muchos directores se negaron a participar del mismo o lograron evadirlo (hay cédulas censales en los cuales los directores del colegio no quisieron aportar datos y, a su vez, hay colegios que directamente no aparecen como por ejemplo el escocés). Por ello, relevamos los avisos de colegios ingleses publicados en el periódico inglés The Standard ${ }^{50}$ y en el Handbook of the River Plate de los

\footnotetext{
49 AGN, Buenos Aires-Argentina, Sala VII 1405 a 1414. Los resúmenes del censo se encuentran en el Registro Estadístico de la Provincia de Buenos Aires del año 1872.

50 Hemos relevado al azar los siguientes años del Standard, concentrándonos en el primer trimestre del año, que era cuando empezaba el año escolar y se multiplicaban la cantidad de anuncios: 1865, 1866, 1867, 1868, 1876, 1877, 1878,1879, 1880.
} 
hermanos Mulhall de 1869. Mientras que el censo sólo nos muestra unos 20 colegios ingleses, en la prensa figuran avisos publicitarios de unos 65 colegios, aunque es posible que algunos de éstos colegios no existieran en 1873 (ya sea porque cerraron antes o porque abrieron sus puertas después) y otros no estaban ubicados en la ciudad de Buenos Aires (aunque apuntaban a un público citadino). En total, entonces, contando los colegios anunciados en The Standard, en el Handbook de Mulhall y los que figuraban en el censo de 1872 había en Buenos Aires, entre 1860 y 1880, unos 79 colegios ingleses que operaban en Buenos Aires (aunque unos diez lo hacían en las afueras de la ciudad $)^{51}$, duplicándose la cantidad de establecimientos ingleses en relación al período anterior.

Aquellos establecimientos radicados en la ciudad de Buenos Aires se concentraba preferiblemente en el centro, en los alrededores de la Plaza Victoria, igual que en las décadas anteriores. Allí se concentraba también la mayoría de la población residente en Buenos Aires $^{52}$ y en consecuencia la mayoría de los colegios de particulares. En 1860, en la zona del centro estaban establecidos el $40 \%$ de las escuelas de particulares de varones y el $50 \%$ de los alumnos (aunque para el caso de las escuelas de mujeres este porcentaje era menor, $23 \%$ y $28 \%$ respectivamente $)^{53}$. Hacia fines de la década de 1870 , no obstante, el centro comenzó a perder primacía (sólo el 26\% de las escuelas estaban asentadas y asistían el $26 \%$ de los alumnos de escuelas particulares solamente $)^{54}$. ¿Quiénes eran los alumnos que asistían a éstos colegios? A diferencia del período anterior carecemos de información sobre los niños que acudían a éstos establecimientos. Sólo disponemos de un listado de alumnos con los resultados de los exámenes de navidad del Anglo Argentine Seminary de Reynolds de 1880 publicado en el Standard ${ }^{5}$. Según este, de 40 alumnos que tomaron los exámenes, sólo uno tenía apellido inglés. Si bien es posible que algunos fueran hijos de matrimonios mixtos (padre nativo y madre extranjera), de todos modos este perfil nos muestra una escuela inglesa abierta para todo tipo de alumnos.

51 The Standard, Mulhall, Handbook of the River Plate (Buenos Aires: edición del autor, 1869), AGN, Buenos Aires-Argentina, Sala VII 1405 a 1414, Censo Nacional de Escuelas.

52 AGN, Buenos Aires-Argentina, Censo Nacional de 1869.

53 AGN, Buenos Aires-Argentina, Registro Estadístico del Estado de Buenos Aires, 1860.

54 AGN, Buenos Aires-Argentina, Registro Estadístico de la Provincia de Buenos Aires, 1879. Véase: James Scobie, Buenos Aires del centro a los barrios (Buenos Aires: Solar Hachette, 1977).

55 The Standard, 29/01/1880. 


\section{CONCLUSIÓN}

\section{Las escuelas particulares inglesas}

Los colegios ingleses que se establecieron en Buenos Aires entre 1820 y 1880 no buscaron cohesionar a la población angloparlante en tanto colegios étnicos. Por el contrario, en muchos casos apuntaron a un mercado muchos más amplio que incluía a nativos, extranjeros y angloparlantes. Para muchos británicos éstos colegios pudieron haber funcionado como vehículos que facilitaron su integración a la sociedad nativa, dado que a muchos de éstos establecimientos concurrían niños angloparlantes y nativos, se enseñaba español e inglés y se evitaba la enseñanza religiosa. Algunos testigos ocasionales, como los viajeros ingleses que circularon por la región en la primera mitad del siglo diecinueve, observaron este fenómeno y sorprendidos lo registraron en sus memorias de viaje. Por ejemplo, un inglés desconocido encontró que "En las escuelas... es hoy el inglés una asignatura de rigor, y dado el continuo intercambio que tienen criollos con ingleses, norteamericanos y otras personas que bablan inglés, la conveniencia de aprenderlo será cada día más patente" ${ }^{256}$. Esto empujó a que muchos criollos mandaran a sus hijos a colegios angloparlantes para que aprendieran inglés, el idioma que comenzó a cobrar gran relevancia para los negocios locales, así como teneduría de libros y aritmética.

Las escuelas inglesas, a su vez, debieron aceptar a todo tipo de niños para asegurar un caudal suficiente de alumnos que les permitiera subsistir. No podían brindar una educación sesgada a la población angloparlante dado el limitado tamaño de la población británica (el censo municipal de 1855 registró una población británica de unas 1.900 personas $)^{57}$ y la creciente competencia que había entre colegios ingleses. La posibilidad de aprender inglés y contabilidad en un país donde las relaciones con Gran Bretaña se habían estrechado a partir de la crisis colonial y se habían fortalecido con la firma del Tratado de Amistad, Navegación y Libre Comercio en 1825 y en los años siguientes a través del continuo contacto comercial entre ambos países; la oferta de una enseñanza tanto en español como en inglés; y la promesa de excluir cualquier tipo de instrucción religiosa (muy importante para los niños criollos católicos que quisieran asistir a los colegios regenteados por protestantes así como para evitar los controles estatales bajo el rosismo) transformaron a las escuelas angloparlantes en opciones atractivas para los nativos. Muchos criollos debieron haber mandado a sus hijos a éstos colegios con el objetivo de que éstos adquirieran los conocimientos necesarios (inglés y teneduría de libros

$56 \quad$ Un inglés. Cinco años: 118 (el resaltado es nuestro).

57 AGN, Buenos Aires-Argentina, VII 1391 a 1404 Censo Municipal 1855.

Rev. hist.edu.latinoam - Vol. 14 No. 18, enero - junio 2012 - ISSN: 0122-7238 - pp. 183 - 210 
principalmente) para poder estrechar vínculos con quienes, en ese momento, ejercían un importante control sobre el comercio local. A su vez, muchas de estas escuelas estaban regenteadas por maestros calificados (como vimos algunos de ellos habían estudiado en Inglaterra o Escocia antes de emigrar a Buenos Aires y contaban con una formación universitaria).

De este modo, las escuelas inglesas desempeñaron un papel relevante en el escenario educativo local. Ofrecían una educación con asignaturas variadas y de mayor complejidad que las escuelas públicas y las de otras particulares llegando a educar a miembros destacados de la sociedad local presentándose como una alternativa al sistema educativo estatal precario o inexistente. Asimismo, dado que éstos colegios eran concurridos por ingleses y escoceses, en muchos casos funcionaron como vehículos que facilitaron la integración de los británicos a la sociedad nativa. Allí los niños aprendían el idioma local, se les enseñaban elementos que les permitiría ingresar al mercado laboral local, se evitaba la enseñanza de la fe protestante y se edificaba un espacio de socialización primaria entre los niños locales y los británicos que concurrían a ellas.

\section{Cuadro A: Materias ofrecidas en las escuelas de particulares e inglesas en porcentajes}

\begin{tabular}{|lcc|}
\hline \multicolumn{1}{|c}{ Materia } & $\begin{array}{c}\text { Escuelas de } \\
\text { particulares } \\
\text { 1835-1851 }\end{array}$ & $\begin{array}{c}\text { Escuelas inglesas }^{58} \\
\text { 1833, 1837, 1838, 1843, 1845, 1851 }\end{array}$ \\
\hline Aritmética mercantil & 35 & 71 \\
Astronomía & 11 & 14 \\
Costura y bordado & 83 & 14 \\
Danza & 20 & 43 \\
Dibujo & 54 & 43 \\
Francés & 66 & 71 \\
Geografía & 60 & 86 \\
Historia & 31 & 29 \\
Inglés & 63 & 71 \\
Italiano & 17 & 0 \\
Latín & 65 & 57 \\
Música & 51 & 29 \\
Religión & 80 & 29 \\
Teneduría de libros & 56 & 71 \\
Español & s/d & 57 \\
Geometría & s/d & 29 \\
Numero de escuelas & 35 & 6 \\
\hline
\end{tabular}

Fuente: Newland, Buenos Aires no es: 167, British Packet 13/4/1833, 14/10/1837, 2/6/1838, 14/10/1843, 3/5/1845, 3/5/1845, 5/4/1851

58 Colegio de Bradish, Commercial Academy, Colegio Argentino de San Martín, colegio de George Clark, English School 


\section{Cuadro B: Materias que se enseñan en los colegios angloparlantes de la ciudad de Buenos Aires en porcentaje (1872)}

\begin{tabular}{|ccc|}
\hline & $\begin{array}{c}\text { Escuelas } \\
\text { particulares } \\
\%\end{array}$ & $\begin{array}{c}\text { Colegios } \\
\text { ingleses }\end{array}$ \\
Lectura & 91,60 & 100 \\
Escritura & 93,13 & 100 \\
Aritmética & 90,84 & 100 \\
Algebra & 19,08 & 30 \\
Geometría & 25,95 & 20 \\
Dibujo & 38,17 & 65 \\
Geografía & 80,15 & 95 \\
Historia & 61,83 & 85 \\
Física & 12,98 & 15 \\
Química & 10,69 & 15 \\
Historia natural & 45,04 & 20 \\
Agricultura & 7,63 & 20 \\
Castellano & 84,73 & 100 \\
Francés & 58,78 & 85 \\
Inglés & 38,93 & 90 \\
Italiano & 17,56 & 10 \\
Alemán & 7,63 & 15 \\
Latín & 20,61 & 40 \\
Otras lenguas & 3,05 & 10 \\
Canto & 22,14 & 25 \\
Música instrumental & 38,17 & 60 \\
Labores de mano & 54,96 & 50 \\
Otras materias & 22,90 & 30 \\
& 120 & 20 \\
\hline
\end{tabular}

Fuente: AGN, Buenos Aires-Argentina, Sala VII 1405 a 1414 Censo Nacional de Escuelas

Cuadro C: Niños clasificados por su grado de instrucción en porcentaje (1872)

\begin{tabular}{|c|c|c|}
\hline & $\begin{array}{c}\text { Colegios } \\
\text { Particulares }\end{array}$ & $\begin{array}{l}\text { Colegios } \\
\text { ingleses }\end{array}$ \\
\hline \multirow{3}{*}{$\begin{array}{l}\text { Leen bien con puntación y demás signos ortográficos de toda } \\
\text { clase de escritos en prosa y verso, impresos y manuscritos } \\
\text { Saben escribir períodos al dictado con todos los signos de la } \\
\text { puntación que se requiera } \\
\text { Saben la numeración y las cuatro operaciones con toda clase de } \\
\text { números }\end{array}$} & 33,02 & 47,99 \\
\hline & 29,35 & 35,44 \\
\hline & 20,20 & 24,98 \\
\hline Sabe la teoría de la proporción y sus aplicaciones & 14,18 & 23,14 \\
\hline Saben lo relativo a la pronunciación castellana & 16,27 & 16,63 \\
\hline Saben sintaxis, análisis lógico y composición & 16,16 & 25,90 \\
\hline Saben geografía argentina & 15,55 & 36,62 \\
\hline \multirow[t]{2}{*}{ Tienen nociones generales de geografía, física y política } & 16,27 & 32,61 \\
\hline & 9.086 & 1.521 \\
\hline
\end{tabular}

Fuente: AGN, Buenos Aires-Argentina, Sala VII 1405 a 1414 Censo Nacional de Escuelas 


\section{Cuadro D: Objetos que constituyen las escuelas (1872)}

\begin{tabular}{|c|c|c|}
\hline & $\begin{array}{c}\text { Escuelas } \\
\text { particulares } \\
\% \\
\end{array}$ & $\begin{array}{c}\text { Colegios } \\
\text { ingleses } \\
\% \\
\end{array}$ \\
\hline Mapas & 61,83 & 85 \\
\hline Laminas sobre historia natural & 19,08 & 30 \\
\hline Muestras de dibujo & 29,01 & 50 \\
\hline Reloj & 76,34 & 90 \\
\hline Sólidos geométricos & 16,79 & 20 \\
\hline Globos para geografía & 33,59 & 40 \\
\hline Marco o tablero contador & 34,35 & 50 \\
\hline Aparatos de física & 8,40 & 15 \\
\hline Pizarras murales & 69,47 & 80 \\
\hline Biblioteca & 50,38 & 60 \\
\hline En general buen tren & 40,46 & 55 \\
\hline $\mathbf{N}=$ & 120 & 20 \\
\hline
\end{tabular}

Fuente: AGN, Buenos Aires-Argentina, Sala VII 1405 a 1414 Censo Nacional de Escuelas

\section{REFERENCIAS}

Lilia Ana Bertoni, Patriotas, cosmopolitas y nacionalistas. La construcción de la nacionalidad argentina a fines del siglo XIX (Buenos Aires: Fondo de Cultura Económica, 2001).

María Bjerg, Historias de la inmigración en la Argentina. (Buenos Aires: Edhasa, 2009).

Marta Bonaudo, Liberalismo, Estado y Orden Burgués (1852-1880) (Buenos Aires: Sudamericana, 1999 tomo IV).

José Bustamante Vismara, Las escuelas de primeras letras en la campaña de Buenos Aires (18001860). (La Plata: Asociación Amigos del Archivo Histórico, 2007).

Fernando Devoto, Historia de la inmigración en la Argentina (Buenos Aires: Sudamericana, 2004).

Luigi Favero "Las escuelas de las sociedades italianas en la Argentina (1866-1914)" en La inmigración italiana en la Argentina, (2000); eds. Fernando Devoto y, Gianfausto Rosoli (Buenos Aires: Biblos, 2000).

Noemí Goldman, Revolución, república, confederación (1806-1852) (Buenos Aires: Sudamericana, 1998).

Tulio Halperin Donghi, Revolución y Guerra (Buenos Aires: Siglo XXI, 1994).

Tulio Halperin Donghi, Una nación para el desierto argentino (Buenos Aires: CEAL, 1995).

Maxine Hanon, Diccionario de británicos en Buenos Aires (Buenos Aires: Gutten Press, 2005). 
Ricardo Levene, Historia de la nación Argentina (desde los orígenes hasta la organización definitiva en 1862) (Buenos Aires: Planeta. Tomo VI,), 261-275.

Lucía Lionetti, "Continuidades y discontinuidades de las políticas públicas en la educación de las 'madres de ciudadanos' en la Argentina del siglo XIX”' en Educación, género y ciudadanía. Las mujeres argentinas: 1700-1943. Editado por Pilar Pérez Cantó y Susana Bandieri (Buenos Aires: Miño y Dávila, 2005).

Lucía Lionetti, La misión política de la escuela pública. Formar a los ciudadanos de la república (18701916). (Buenos Aires: Miño y Dávila, 2007).

José C. Moya, Primos y extranjeros. La inmigración española en Buenos Aires, 1850-1930 (Buenos Aires: Emecé, 2004).

Mulhall, Handbook of the River Plate (Buenos Aires: edición del autor, 1869).

Carlos Newland, Buenos Aires no es pampa. La educación elemental porteña. 1820-1860. (Buenos Aires: Grupo Editor Latinoamericano, 1992).

Carlos Newland, "Enseñanza elemental y superior (1810-1862)" en Nueva historia de la nación argentina, (2007).

Juan P. Ramos, Historia de la instrucción primaria en la república Argentina 1810-1910 (Atlas escolar) (Buenos Aires: Peuser, 1910).

Antonio Salvadores, La instrucción primaria desde 1810 hasta la sanción de la ley 1420 (Buenos Aires: Talleres Gráficos, Consejo Nacional de Educación, 1941).

Antonio Salvadores, "El decreto del 26 de mayo de 1844, sobre las escuelas de la provincia de Buenos Aires". Boletín del Instituto de Investigaciones Históricas. Vol: VIII Nº 39 (1929): 41-63.

Paula Seiguer, "La iglesia anglicana en la Argentina y la colectividad inglesa. Identidad y estrategias misionales, 1869-1930" (Tesis de Doctorado en Universidad de Buenos Aires, 2009).

Alina Silveira, "Los británicos en Buenos Aires: movimientos poblacionales, pautas matrimoniales e inserción económica (1800-1850)" (Tesis de Maestría en Universidad de San Andrés, 2008).

Lawrence Stone, "Literacy and Education in England, 1640-1900" en Past \& Present $\mathrm{N}^{\circ} 42$, (1969): 69-139.

Gillian Sutherland, "Education" en The Cambridge Social History of Britain 1750-1950. Social Agencies and institutions editado por F. M. L. Thompson (Cambridge: Cambridge University Press, 1996 Vol. 3).

Mark Szuchman "Childhood Education and Politics in Nineteenth-Century Argentina: the Case of Buenos Aires", Hispanic American Historical Rreview. Vol.70 No. 1 (1990): 109-138. 
Mark Szuchman, Order, family, and community in Buenos Aires. 1810-1860 (Stanford: Stanford University Press, 1988).

Un Inglés. Cinco años en Buenos Aires, 1820-1825 (Buenos Aires: Solar/Hachette. 1962: 117).

José Antonio Wilde, Buenos Aires desde setenta años atrás (Buenos Aires: Eudeba, 1960).
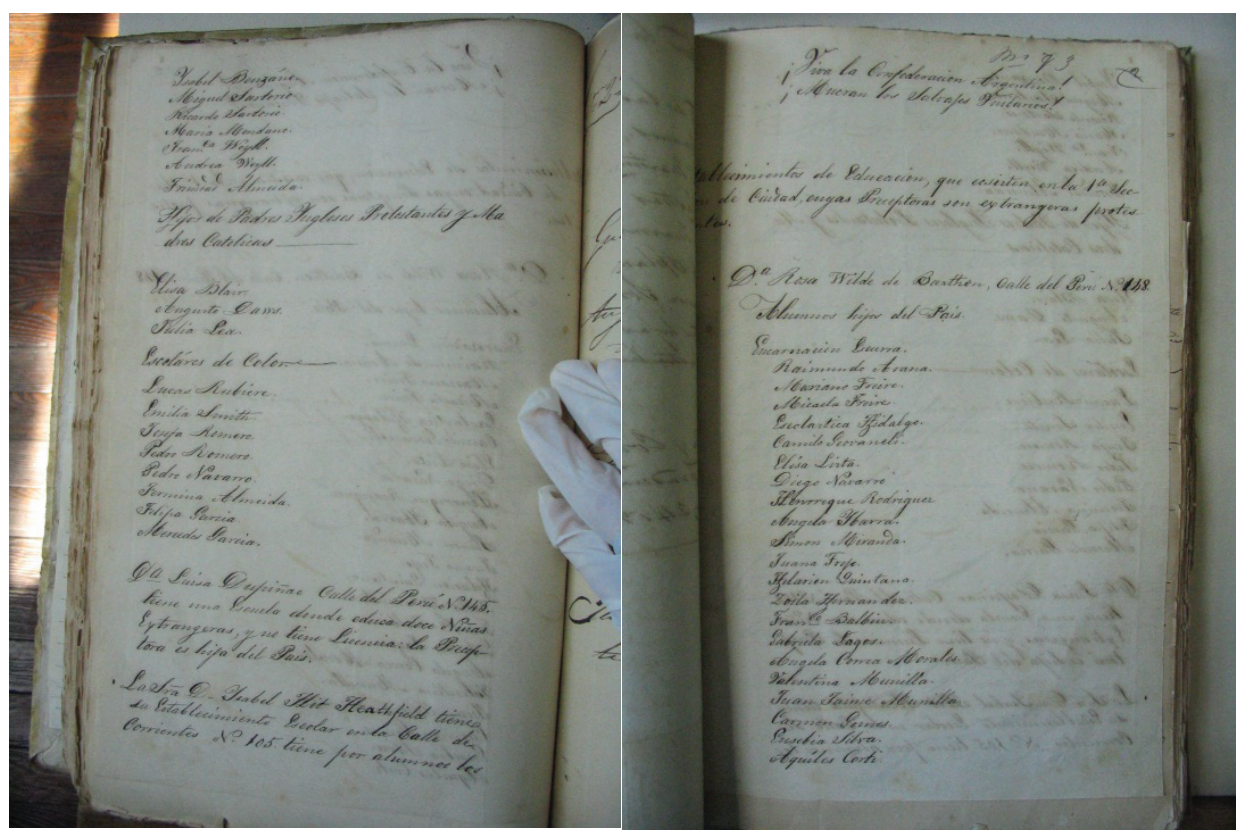

Registros policiales bajo el gobierno de Rosas de la escuela de Rosa Wilde de Barton, AGN Sala X 33-5-10 Libro 164 (1848)

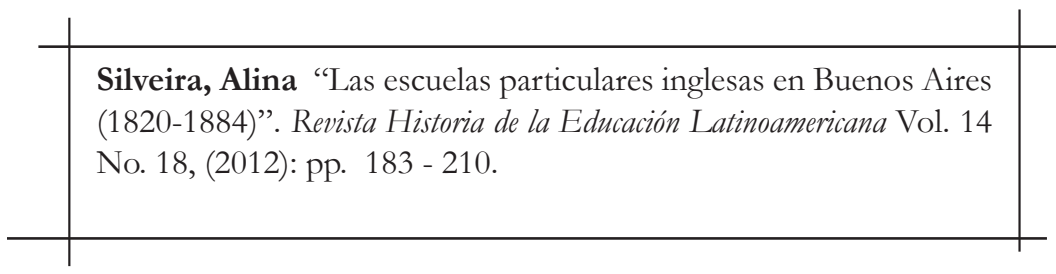

